\title{
$\alpha$-Tocopherol and Ketorolac on Pain in Long Evans Rats
}

\author{
Mahadi Abdur Rouf', Shelina Begum², Taskina Ali, Mizanur Rahman ${ }^{4}$, Shahriar Masood $^{5}$
}

\begin{abstract}
Background: Alpha-tocopherol $(\alpha \mathrm{T})$ is a form of vitamin $\mathrm{E}$ that is widely known to be one of the reactive oxygen species scavengers (ROS) and it has been shown to have analgesic effects in different animal and human studies. But comparison of these effects with similar effects of ketorolac tromethamine (KT) and their combination have not been established. Objective: To assess the effects of $\alpha \mathrm{T}$ on pain and also compare them with those of the combinations of $\alpha \mathrm{T}$ with KT in rat models.Methods: This experimental study was conducted in the Department of Physiology, Bangabandhu Sheikh Mujib Medical University (BSMMU), Dhaka, from March 2015 to February 2016. For this, 20 (twenty) Long Evans rats $(215 \pm 35 \mathrm{gm})$ of both sexes were divided into control (A, with $5 \mathrm{~mL} / \mathrm{kg}$ normal saline) and experimental (B1, with $500 \mathrm{mg} / \mathrm{kg} \alpha \mathrm{T}$; B2, with $10 \mathrm{mg} / \mathrm{kg} \mathrm{KT}$; B3, with $\alpha \mathrm{T}+\mathrm{KT}$ ) groups with 5 (five) rats in each group. All the drugs and vitamins were administered intraperitoneally in a single dose, just one hour before formalin test. To evaluate the effect of treatments on nociceptive pain, early phase $\left(1^{\text {st }}-5^{\text {th }}\right.$ minutes); on central analgesic system, interphase ( $6^{\text {th }}-15^{\text {th }}$ minutes $)$; and on inflammatory pain, late phase $\left(16^{\text {th }}-60^{\text {th }}\right.$ minutes $)$ of the formalin test, were observed. In all phases, total frequency of jerking and total duration of flexing and licking of the right hind paw were counted after administration of subcutaneous formalin $(50 \mu \mathrm{L}, 2.5 \%)$ injection. Statistical analysis was done by ANOVA, followed by Bonferroni post hoc test. In the interpretation of results, $\mathrm{p} \leq 0.05$ was considered as significant. Results: $\alpha \mathrm{T}$ lowered flexing and licking duration significantly $(\mathrm{p} \leq 0.001)$ in early and late phases. KT lowered flexing and licking duration significantly $(\mathrm{P}<0.001)$ in late phase of formalin test. On the other hand, combination of $\alpha \mathrm{T}$ and KT significantly $(\mathrm{p} \leq 0.001)$ lowered both the study variables in early and late phase of formalin test. Conclusion: From this study it may be concluded that, $\alpha \mathrm{T}$ possesses analgesic effects and combination of $\alpha \mathrm{T}$ with $\mathrm{KT}$ is more effective than those of their individual administration.
\end{abstract}

Keywords: Pain, Analgesic, $\alpha$-tocopherol, Ketorolac, Formalin Test.

J Bangladesh Soc Physiol. 2017, June; 12(1): 21-27

For Authors Affiliation, see end of text.

http://www.banglajol.info/index.php/JBSP

\section{Introduction}

H

uman beings have been trying to explain pain for as long as they have been experiencing it. ${ }^{1}$ It is one of the main symptoms of many diseases, and can considerably interfere with a person's quality of life. $^{2}$ As an unpleasant sensory and emotional experience, pain is associated with actual or potential tissue damage hence, discomfort and

Received 20 Feb 2017; $\quad$ Accepted 18 May 2017 distress follows to make it single most common reason for a visit to physicians. ${ }^{3,4}$ Pain is a complex and multi-dimensional appreciation. Etiologically, it has been classified into nociceptive, inflammatory, neuropathic and functional type. ${ }^{7,8}$

To overcome the obstinacy of pain, proper pain management is a must. There are a various classes of analgesic drugs available for pain management. 
To measure the efficacy of different analgesics, pain assessment is very crucial. For the measurement of nociceptive and inflammatory pain behaviors in animal model, the formalin test is one of the valid and reliable assessment tool. This test shows an early phase ( $\left(1^{\text {st }}-5^{\text {th }}\right.$ minutes $)$ which reflects direct activation of nociceptors, an interphase $\left(6^{\text {th }}-15^{\text {th }}\right.$ minutes $)$ showing the activation of central analgesic system and a late phase $\left(16^{\text {th }}-60^{\text {th }}\right.$ minutes $)$ reflecting pain due to inflammation ${ }^{9}, 10$.

Ketorolac tromethamine (KT) is an extremely effective and potent non-steroidal intiinflammatory drug (NSAID) commonly used for short term management of severe acute pain associated with inflammation, that requires immediate analgesia. ${ }^{11,12}$ Long term use of KT is not indicated due to its association with peptic ulcer and many other systemic manifestations like, coagulation disorder, nephrotoxicity as well as severe impairment of cardiac, cerebral and hepatic functions ${ }^{12-15}$.

In recent years, many studies have been conducted throughout the world with an aim to find alternatives to the traditional analgesic drugs in order to replace them or at least to reduce the duration of drug therapy, to minimize their adverse effects. Therefore, to minimize harmful side effects of traditional analgesics, different vitamins are being used concomitantly ${ }^{15,16}$.

In 1922, Evans and Bishop discovered vitamin E, a fat soluble vitamin and $\alpha$-tocopherol $(\alpha \mathrm{T})$ is the most biologically active among its eight naturally active forms ${ }^{17-19} \cdot \alpha$-tocopherol, which is a relatively easy reactive oxygen species (ROS) scavenger, has also proved its antinociceptive effects in a animal experimental study ${ }^{22}$. This vitamin's antinociceptive effect is thought to arise from anti-inflammatory mechanism and it is anticipated to be effective in controlling both acute and chronic pain. Moreover, it has been suggested that, $\alpha \mathrm{T}$ might act synergistically with NSAID to reduce gastric inflammation and pain of peptic ulcer disease $\mathrm{e}^{20-23}$.

However, it has also been reported that, single dose of $10 \mathrm{mg} / \mathrm{kg} \mathrm{KT}$ was a sub effective dose against nociceptive as well as inflammatory pain. ${ }^{24}$ It has also been proposed that combined administration of analgesics with antioxidants in pain treatment might be applied to decrease the doses of analgesics and to prevent negative impact of ROS as well ${ }^{25}$.

But, still the information regarding this matter is not sufficient enough to reach any final conclusion. Furthermore, no reported data was available to compare the combined analgesic effects of $\alpha \mathrm{T}$ with $\mathrm{KT}$ to that of their individual administration on nociceptive and inflammatory pain.

On the basis of this background, the present study has been designed to evaluate the analgesic effects of single administration of Ketorolac as well as its combination with $\alpha$-tocopherol to compare their combined analgesic effects with their individual administration in Long Evans rats.

\section{Methods}

This experimental study was conducted in the Pain laboratory of the Department of Physiology of Bangabandhu Sheikh Mujib Medical University (BSMMU), Dhaka, from March 2015 to February 2016. All experiments and animal care were performed according to the guidelines set in the 'Manual for Care and use of Laboratory Animals' by the Animal Experimentation Ethics Committee (AEEC) of the International Center for Diarrhoeal Disease Research, Bangladesh (icddr,b 2002) ${ }^{26}$.

\section{Procurement and maintenance of animals}

Twenty (20) healthy adult Long Evans rats weighing 180 to $250 \mathrm{gm}^{15}$ of both sexes ${ }^{24,27,28}$ were obtained from the animal house of Bangladesh University of Health Sciences (BUHS), Dhaka. All the rats were kept in the Pain laboratory of the Department of Physiology, BSMMU, where they were housed in specially built plastic cages with 6 rats per cage under a 12/12 hour light/dark cycle ${ }^{29-31}$. The ambient room temperature was maintained at around 27 to $28^{\circ} \mathrm{C}$, corresponding to the thermo-neutral zone for rodents ${ }^{32,33}$. All the rodents had free access to standard laboratory food and cooled boiled water ${ }^{15}$. They were kept there for a period of seven (7) consecutive days for environmental acclimatization, prior to the experiment. To avoid circadian influences 
all the experiments were performed at day time between 08:00 and 16:00 hours. ${ }^{34}$

\section{Dose schedule}

The $\alpha$-tocopherol (Biopharma, Bangladesh) and Ketorolac tromethamine (Novartis, Bangladesh) were obtained in granular form and were dissolved in normal saline $(5 \mathrm{ml} / \mathrm{kg}$ body weight). On the basis of drugs and vitamin administration, all the rats were divided into four (4) groups (5 rats/ group). Of them control group (A) received only normal saline $(5 \mathrm{ml} / \mathrm{kg} \text { body weight })^{34}$, Vitamin treated group(B1) received $\alpha \mathrm{T}(500 \mathrm{mg} / \mathrm{kg}$ body weight $)^{15}$, ketorolac treated group(B2) received ketorolac tromethamine $(\mathrm{KT})(10 \mathrm{mg} / \mathrm{kg}$ body weight $)^{24}$, combination treated group (B3) received $\alpha \mathrm{T}(500 \mathrm{mg} / \mathrm{kg}$ body weight) and KT $(10 \mathrm{mg} / \mathrm{kg}$ body weight) in equal volume to that of normal saline, respectively. Just an hour after intraperitoneal (i.p) ${ }^{15,22}$ administration of drug and vitamin, all the rats underwent formalin test.

\section{Formalin test}

In order to make the rats accustomed to the test environment, all the rats were placed in the observation chamber $\left(34 \mathrm{X} 34 \mathrm{X} 34 \mathrm{~cm}^{3}\right)$ of the plexiglass formalin box in pairs for fifteen (15) minutes daily for four (4) consecutive days, and singly for three (3) days prior to the test ${ }^{9,}, 35$. On the day of experiment, each rat was intraperitoneally injected with normal saline or áT or KT or combinations thereof in accordance with the experimental paradigm being followed. Just

A

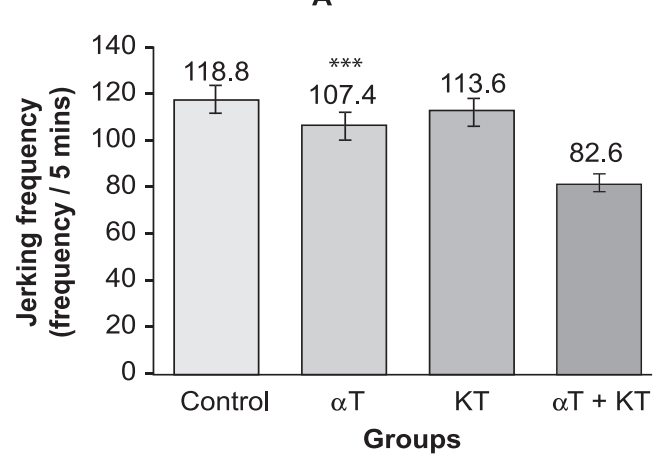

one (1) hour later, the rat was restrained manually by a thick towel and fifty $(50) \mu l$ of dilute $(2.5 \%)$ formalin was injected subcutaneously 35,36 into the planter aspect of the right hind paw with an insulin syringe. Immediately thereafter, the animal was placed in the observation chamber of the plexiglass formalin test box, and pain behaviors were observed for consecutive sixty (60) minutes. A mirror fixed at an angle of $45^{\circ}$ beneath the transparent floor of the chamber was used to facilitate unhindered observation. The first five (5) minutes $\left(1^{\text {st }}-5^{\text {th }}\right)$ was considered as the early phase, the next ten (10) minutes $\left(6^{\text {th }}-15^{\text {th }}\right)$ as the interphase, and the last 45 minutes $\left(16^{\text {th }}-60^{\text {th }}\right)$ as the late phase. During observation, the total number of jerking and the total duration of flexing plus licking of the injected paw (in seconds) per 5minutes time block was also recorded. A stopwatch was used to count the time $e^{9,30,35}$.

Results were expressed as mean \pm SEM and the data were statistically analyzed by ANOVA, followed by Bonferroni post hoc test. In the interpretation of results $\mathrm{p} \leq 0.05$ was accepted as the level of significance.

\section{Results}

Antinociceptive effect

In this study, in the early phase of formalin test, the mean values of both variables were lowered in all the study groups than those of control group. However, this decrement was statistically significant $(\mathrm{p} \leq 0.001)$ in the rats with single $\alpha \mathrm{T}$ as well as in the rats with combined treatment of $\alpha \mathrm{T}$ and KT, in both variables (Figure 1).

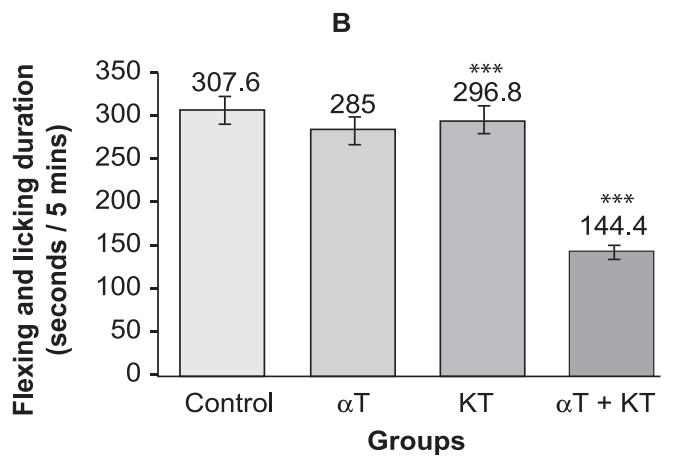

Figure 1: Frequency of jerking (A) and duration of flexing and licking (B) in early phase $\left(1^{\text {st }}-5^{\text {th }}\right.$ minutes) of formalin test in different groups of rats. Each bar symbolizes for mean $\pm \mathrm{SE}$ for 5 rats. $* * *=\mathrm{p} \leq 0.001$, compared to those of control. $\alpha \mathrm{T}=\alpha$-Tocopherol; $\mathrm{KT}=$ Ketorolac tromethamine. 
Similarly in the interphase $\left(6^{\text {th }}-15^{\text {th }}\right.$ minutes $)$ of formalin test, combined administration of KT and $\alpha \mathrm{T}$ showed significant lowering of the jerking frequency ( $\mathrm{p} \leq 0.005)$ (Figure $2 \mathrm{~A}$ ) as well as of the duration of flexing and licking $(\mathrm{p} \leq 0.001)$ (Figure $2 \mathrm{~B})$ when compared to control (Figure 2).
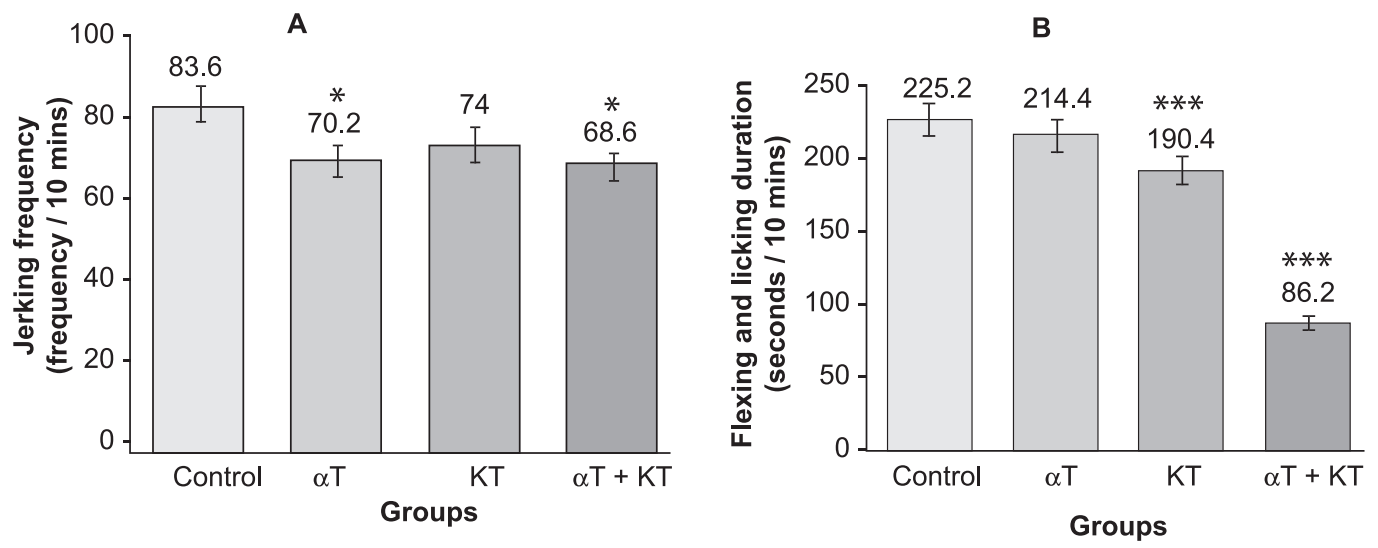

Figure 2: Frequency of jerking (A) and duration of flexing and licking (B) in the interphase $\left(6^{\text {th }}-15^{\text {th }}\right.$ minutes) of formalin test in different groups of rats. Each bar symbolizes for mean $\pm \mathrm{SE}$ for 5 rats. $* * *=\mathrm{p} \leq 0.001$ and $*=\mathrm{p} \leq 0.05$, compared to those of control. $\alpha \mathrm{T}=\alpha$-Tocopherol; KT=Ketorolac tromethamine.

However, in late phase of formalin test, both the study groups showed significant reduction ( $\mathrm{p} \leq 0.001)$ in both pain variables compared to that of the control group (Figure 3 ). In addition, rats treated with combined administration showed statistically significant $(\mathrm{p} \leq 0.001)$ reduction in the duration of flexing and licking than that of individual administration of KT in this phase (not shown in figure 3).
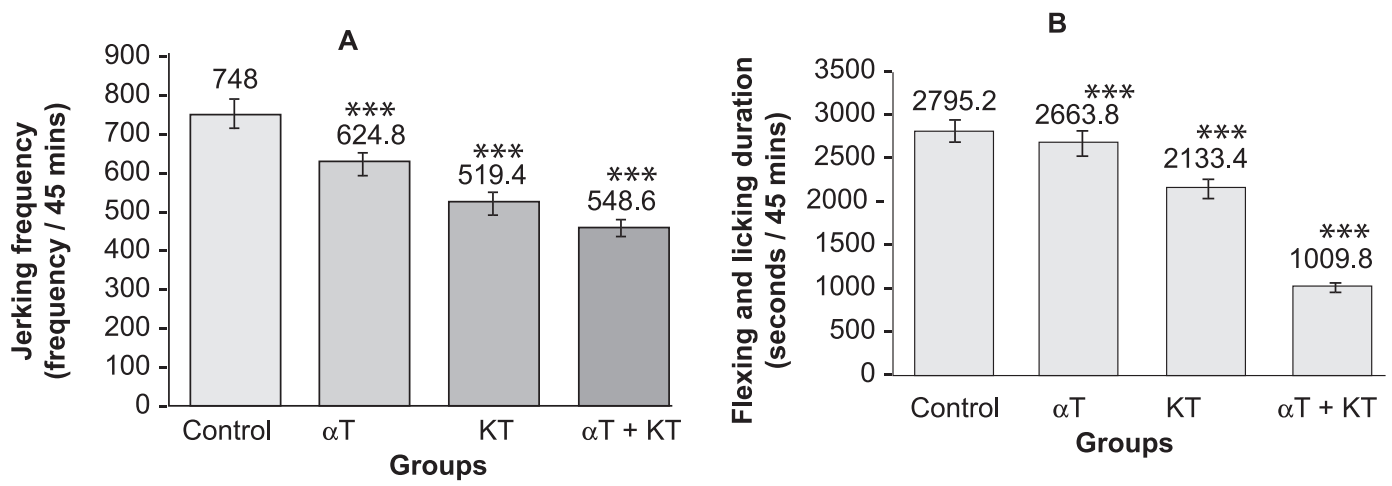

Figure 3: Frequency of jerking (A) and duration of flexing and licking (B) in the late phase $\left(16^{\text {th }}-60^{\text {th }}\right.$ minutes) of formalin test in different groups of rats. Each bar symbolizes for mean \pm SE for 5 rats. $* * *=\mathrm{p} \leq 0.001$, compared to those of control and $* * *=\mathrm{p} \leq 0.001 . \alpha \mathrm{T}=\alpha$-Tocopherol; KT=Ketorolac tromethamine. 


\section{Discussion}

In this study, individual administration of $\alpha \mathrm{T}$ lowered the nociceptive pain as evidenced by reduction of frequency of jerking as well as duration of flexing and licking in the early phase of formalin test. Similar findings were observed by Majagi et al. $(2011)^{37}$ in different pain models and by Juaira et al. (2014) $)^{15}$ in different animal models. On the contrary, individual administration of KT did not lower the nociceptive pain in our study. Similar finding was observed by Banode et al. (2012) 24 . However, the combined administration of $\alpha \mathrm{T}$ and KT lowered this pain, significantly. No similar study was found to support this observation. It has been suggested that, $\alpha \mathrm{T}$ increases $\mathrm{K}^{+}$conductance in post synaptic membrane causing hyperpolarization of dorsal horn neuron. Hence, decrease pain transmission ${ }^{39,40}$. On the other hand, KT also has a role on increasing $\mathrm{K}^{+}$conductance ${ }^{40,45}$, which might be synergized by administration of $\alpha \mathrm{T}$ and caused more hyperpolarization of dorsal horn neuron and decreased pain conduction in our study as evidenced by significant difference in nociceptive pain variables in rats with individual $\alpha \mathrm{T}$ administration and combined administration of $\alpha$ T with KT.

Moreover in the present study, individual administration of áT showed increment of central analgesic activity as evidenced by reduction of jerking in the interphase of formalin test. Similar findings were observed by Majagi et al (2011) ${ }^{37}$. and Juaira at al. (2014) $)^{15}$ in different animal models. Again, individual administration of KT as well as its combination with $\alpha \mathrm{T}$ also showed to increase the central analgesic activity as evidenced by reduction of both its variables. However, the combined administration of $\alpha \mathrm{T}$ and KT showed more effectiveness in central analgesia in comparison to the single administration of vitamin and drug. No similar study was found to support this observation. It has been suggested that, $\alpha \mathrm{T}$ might enhance the activity of GABA (gamma-Aminobutyric acid) in the CNS to diminish pain transmission ${ }^{39}$. On the other hand KT might inhibit the NMDA (Nmethyl-D-aspartate) induced excitation of NMDA receptors in the CNS to diminish pain transmission ${ }^{46}$. It is assumed that any of the above mentioned mechanisms might be activated together and synergistically acted to cause more central analgesic effect after combined administration of $\alpha \mathrm{T}$ and $\mathrm{KT}$.

Furthermore in our study, individual administration of $\alpha \mathrm{T}$ lowered inflammatory pain as evidenced by reduction of frequency of jerking as well as duration of flexing and licking in the late phase of formalin test. Similar findings were observed by Majagi et al (2011). ${ }^{37}$ and Juaira et $\mathrm{al}(2014)^{15}$ in different animal models. In addition, individual administration of KT also lowered inflammatory pain as evidenced by reduction of frequency of jerking as well as duration of flexing and licking in the late phase of formalin test. Similar response was also reported by other researchers after single administration of ketorolac at different doses in different pain models ${ }^{32,36,38}$. However, the combined administration of $\alpha \mathrm{T}$ and KT lowered this pain, significantly. No similar study was found to support this observation. It has been suggested that, $\alpha$ Tmight reduce inflammatory pain by decreasing plasma NO (Nitric oxide), TNF- $\alpha$ (Tumor necrosis factor - alpha), $\mathrm{PGE}_{2}$ (Prostaglandin E type 2) ${ }^{41-44}$. In addition, KT also reduces inflammatory mediators by inhibiting the prostaglandin synthesis by competitively blocking cyclooxygenase $(\mathrm{COX})^{40,45}$. So, combined administration of $\alpha \mathrm{T}$ and KT might play a synergized role in reducing inflammatory mediators hence, inflammatory pain.

\section{Conclusion}

From this study, it can be concluded that combined administration of $\alpha \mathrm{T}$ and KT may be more effective in lowering pain than the individual 
administration of KT. This data may apprise the clinicians and general populations to used $\alpha \mathrm{T}$ along with KT for better management of pain. Although further experimental study is needed to elucidate the exact component and mechanism for these effects.

\section{Conflict of interest: None}

\section{Authors' affiliations}

1. *Mahadi Abdur Rouf, Assistant Professor, Department of Physiology, Northern International Medical College, Dhaka, Bangladesh. Email: mahadi@doctor.com, Tel: +8801841370700

2. Shelina Begum, Professor, Department of Physiology, Bangabandhu Sheikh Mujib Medical University (BSMMU), Dhaka, Bangladesh. Email: shelina1982@gmail.com

3. Taskina Ali, Associate Professor, Department of Physiology, Bangabandhu Sheikh Mujib Medical University (BSMMU), Dhaka, Bangladesh. Email: taskinadr@gmail.com

4. Md. Mizanur Rahman, Assistant Professor, Department of Physiology, Enam Medical College, Savar, Bangladesh. Email: mizandr001@gmail.com

5. Shahriar Masood, Assistant Professor, Department of Physiology, Jahurul IslamMedical College, Bhagalpur, Bajitpur, Kishoregonj, Bangladesh. Email: shahriarmasood@gmail.com

\section{References}

1. Woolf CJ. What is this thing called pain? J Clin Invest $2010 ; 120(11): 3742-3744$.

2. Loeser JD, Treede RD. The Kyoto protocol of IASP Basic Pain Terminology Pain. 2008; 137(3):473-77.

3. Abbott FV, Fraser MI. Use and abuse of over-thecounter analgesic agents. J Psych Neuro 1998; 23(1):13-34

4. Turk DC, Dworkin RH. What should be the core outcome of clinical pain trials? Arth Res 2004; 6(4):151-154.

5. Woolf CJ.Pain: moving from symptom control toward mechanism-specific pharmacologic management. Anna of Intern Med 2004; 140:441451 .

6. Ridel W, Neeck G. Nociception, pain and antinociception: current concept. Z Rheumatol 2001; 60(6): 404-415

7. Medzhitov R. Inflammation 2010: new adventures of an old flame. Cell 2010; 140:771-776.
8. Nathan C. Points of control of inflammation. Nature 2002; 420(6917): 846-852.

9. Henry JL, Yashpal K, Pitcher GM, Coderre TJ. Physiological evidence that the 'interphase' in the formalin test is due to active inhibition. Pain 1999; 82:57-63.

10. Dubuisson D, Dennis SG. The formalin test: a quantitative study of the analgesic effects of morphine, meperidine, and brain stem stimulation in rats and cats. Pain. 1977; 4(2):161-174.

11. Gillis JC, Brogden RN. Ketorolac. Drugs 1997; 53(1):139-188.

12. Sam T, Mathew S, Gayathri D, Sandhya KV. Formulation and evaluation of ketorolac tromethamine-loaded albumin microspheres for potential intramuscular administration. AAPS Pharm Sci Tech 2007; 8(1): 100-108.

13. Fini A, Garuti M, Fazio G, Alvarez FJ, Holgado MA. Fractal and thermal analysis of sodium and potassium diclofenac salts. J Pharm Sci 2001; 90: 2049-2057.

14. Rainsford KD, Kean WF, Ehrlich GE. Review of the pharmaceutical properties and clinical effects of the topical NSAID formulation, diclofenacepolamine. Curr Med Res Opin 2008; 24(10)

15. Juaira T. Effect of á-tocopherol and its combination with diclofenac on pain and inflammation in rats. [Thesis] [Dhaka (Bangladesh)]: BSMMU. 2014

16. Imtiaz $M$. Effect of vitamin $B_{12}$ and folic acid and their combination on pain and inflammation in rats. [Thesis] [Dhaka (Bangladesh)]: BSMMU. 2011.

17. Edmonds SE, Winyard PG, Guo R, Kidd B, Merry P, Smith AL, Hansen C, Ramm S, Blake DR. Putative analgesic activity of repeated oral doses of vitamin $\mathrm{E}$ in the treatment of rheumatoid arthritis. Ann Rheum Dis 1997; 56: 649-655.

18. Azzi A, Stocker A. Vitamin E: non-antioxidant roles. prog. lipid. Res. 2000; 39: 231-255.

19. Kaya NE. Alpha-tocopherol: looking beyond an antioxidant. Molecular vision 2009; 15: 855-860.

20. Lazzarini M, Salum C, Del Bel EA. Combined treatment of ascorbic acid or alpha-tocopherol with receptor antagonist or nitric oxide synthase inhibitor potentiates cataleptic effect in mice. Psychopharm 2005; 181:71-79.

21. Lu R, Gerhardt WK, Geisslinger G, Schmidtko A. 
Additive antinociceptive effects of a vitamin C and vitamin $\mathrm{E}$ after peripheral nerve injury. PLOs One 2011; 6(12).:

22. Kim MJ, Hong BH, Zhang EJ, Ko YK Lee WH. Antinociceptive effects of Intraperitoneal and intrathecal vitamin $\mathrm{E}$ in rat formalin test. Korean J Pain 2012; 25(4):238-244.

23. Tiwari V, Kuhad A, Chopra K. Neuroprotective Effect of Vitamin E isoforms against chronic alcohol-induced peripheral neurotoxicity: possible involvement of oxidative nitrodative stress. Phytother Res 2012; 26(11):1738-1745.

24. Banode SV, Borkar AS, Badwaik RT. Effect of ketorolac on opioid induced antinociception in rats. Intl J Med Pharm Sci 2012; 3(3):7-13.

25. Rokyta R, Holecek V, Pekarkova J, Racek J, Trefil L, Yamamatova A. Free radicals after painful stimulation are influenced by antioxidants and analgesics. Neuro Endocrinol 2003; 24(5):304-309.

26. Islam KMN, Rahman ASMH, Al-Mahmud KA. Manual for care and use of laboratory animals. Animal resource branch. International Center for Diarrhoeal Disease Research, Bangladesh: 2001.

27. Das et al. Antinociceptive and anti-inflammatory activity of the bark extract of plumeriarubra on laboratory animals. Euro J Med Plants 2013; 3(1): 114-126.

28. Jami MSI, Sultana Z, Ali ME, Begum MM, Haque MM. Evaluation of analgesic and antiinflammatory activities of ethanolic extract of terminaliachebula fruits in experimental animal models. AJPS 2014; 5: 63-69.

29. Abbott FV, Franklin KB, Westbrook RF. The formalin test: scoring properties of the first and second phases of the pain response in rats. Pain 1995; 60(1):91-102.

30. Tajik H, Tamaddonfard E, Hamzeh-Gooshchi N. The effect of curcumin (active substance of turmeric) on the acetic acid-induced visceral nociception in rats. Pak J Biol Sci 2008; 11(2):312314.

31. Ali T, Javan M, Sonboli A, Semnanian S. Evaluation of the antinociceptive and anti-inflammatory effects of essential oil of Nepeta pogonosperma Jamzad et Assadi in rats. DARU J Pharm Sci 2012; $20: 1-8$.

32. França et al.B vitamins induce an antinociceptive effect in the acetic acid and formaldehyde models of nociception in mice. Eur J Pharmacol 2001; 421:157-164.

33. Refinetti R, Horvath SM. Thermopreferendum of the rat: inter- and intra-subject variabilities. Behav Neural Biol 1989; 52(1):87-94.

J Bangladesh Soc Physiol. 2017, June; 12(1): 21-27
34. Moallem SA, Hosseinzadeh H, Farahi S. A study of acute and chronic anti-nociceptive and antiinflammatory effects of thiamine in mice. Iran Biomed J 2008; 12 (3):173-178.

35. McNamara CR, Brehm et al. TRPA1 mediates formalin-induced pain. Proceedings of the National Academy of Sciences 2007; 104 (33): 1352513530 .

36. Reyes-García et al. Analgesic effect of B vitamins in formalin-induced inflammatory pain. Proc West Pharmacol Soc 2001; 44:139-140.

37. Majagi SI, Bhosle TN, Patil PA. Anti-inflammatory and analgesic activity of DL alpha-tocopheryl acetate and its interaction with aspirin in Wister rats. IJDDR 2011; 3(4):86-93.।

38. Medina-Santillán R, Reyes-García G, RochaGonzález HI, Granados-Soto V. B vitamins increase the analgesic effect of ketorolac in the formalin test in the rat. Proc West Pharmacol Soc 2004; 47: 95-99.

39. Nadine C, Ferreira MC, Solal CC, Kadmi CM, Bernad N, Martinez J, Barbanel G, Vignes M, Guiramand J. á-tocopheryl phosphate interact with the cannabinoid system in the rodent hippocampus. Free Radic Biol Med 2011; 51:1643-1655.

40. Barrett KE, Barman SM, Boitano S, Brooks HL. Ganong's Review of Medical Physiology. 23rd. New Delhi: Tata McGraw-Hill; 2010.

41. Alorainy M. Effect of allopurinol and vitamin $\mathrm{E}$ on rat model of rheumatoid arthritis. Intl J Health Sci 2008; 2(1):59-67.

42. Xu JX, Chen XL, Wang J, Wang T. Dietary vitamin E influences the levels of nitric oxide and cytokines in broiler chickens. AAAP 2011; 24(10):14401446.

43. Mol MJ, Rijke YB, Demacker PN, Stalenhoef AF. Plasma levels of lipid and cholesterol oxidation products and cytokines in diabetes mellitus and cigarette smoking: effects of vitamin $\mathrm{E}$ treatment. Atheros 1997; 129(2):169-176.

44. Han SN, Wu D, Ha WK, Beharka A, Smith DE, Bender BS, Meydani SN. Vitamin E supplementation increases $\mathrm{T}$ helper 1 cytokine production in old mice infected with influenza virus. Immunol 2000; 100(4):487-493.

45. Lázaro-Ibáez GG, Torres-López JE, Granados-Soto V. Participation of the nitric oxide-cyclic GMPATP-sensitive $\mathrm{K}^{+}$channel pathway in the antinociceptive action of ketorolac. Euro J Pharm 2001; 426(1-2): 39-44.

46. Sotgiu ML, Biella G, Formaglio F, Merchettini P. Central effect of ketorolac involving NMDA receptors activity. Brain Res 1998; 813(1): 223226. 